EESTI NSV TEADUSTE AKADEEMIA TOIMETISED. 21. KOIDE KEEMIA * GEOLOOGIA. 1972, NR. 4

ИЗВЕСТИЯ АКАДЕМИИ НАУК ЭСТОНСКОЙ ССР. ТОМ 21 ХИМИЯ - ГЕОЛОГИЯ. 1972, №2 4

удК $620.191 .2+614.72$

П. ЛУИГА, РЭЭТ ЛИИВ, П. ТАММИСТЕ *

\title{
КОРРОЗИОННЫЕ ИСПЫТАНИЯ ПРИ ОЦЕНКЕ ЗАГРЯЗНЕННОСТИ АТМОСФЕРНОГО ВОЗДУХА
}

Одним из свойств загрязненного атмосферного воздуха является его корродирующее и деструктивное действие на металлы и другие материалы. С этим связаны две проблемы: защита материалов от действия загрязнителей воздуха и определение степени загрязненности воздуха на основе разрушения материалов. В настоящей работе рассматривается возможность использования стальных образцов для исследования степени загрязненности атмосферного воздуха.

Влияние разных метеорологических условий на коррозию стали изучалось многими учеными [1-4], но лишь некоторые из них уделили внимание роли загрязнителей воздуха при атмоферной коррозии металлов $\left[{ }^{5,6}\right]$ и доказали, что имеется определенная зависимость между скоростью коррозии сталк и загрязненностью воздула.

Скорость коррозии стали зависит от влажности воздуха, температуры и других метеорологических факторов. Для получения данных о зависимости по возможности только от степени загрязненности воздуха, необходимо проводить исследования на небольших территориях с одинаковыми метеорологическими условиями. В Эстонской ССР такие условия сохраняются в районах, не превышающих нескольких десятков километров. Это дает возможность определить центры с наибольшей загрязненностью в городах и загородных районах.

\section{Экспериментальная часть}

Образцы и их установка. Для получения как можно более однородных образцов они были изготовлены из одной партии листовой стали марки «Ст. 2». Размеры образцов были $100 \times 120 \times 1,2$ мм. Один край шириной 20 мм загибали под углом $45^{\circ}$ для прикрепления к месту наблюдения на высоте $3 \mu$ от земли.

Данные, приведенные в таблице, показывают зависимость интенсивности коррозии от характера места и положения установленного образца (образцы прикреплялись к разным объектам в разном направлении).

Электротехнический завод им. Х. Пегельмана. 
Зависимость коррозии от положения образца

\begin{tabular}{|c|c|c|}
\hline \multirow{2}{*}{$\begin{array}{l}\text { Номер о6- } \\
\text { разца }\end{array}$} & \multicolumn{2}{|c|}{\begin{tabular}{c} 
Потеря веса за сутки, \\
\multicolumn{2}{c}{$/ \partial M^{2}$}
\end{tabular}} \\
\hline & I период & II период \\
\hline
\end{tabular}

$\begin{array}{rrr}2 & 9,4 & 8,3 \\ 7 & 9,9 & 10,6 \\ 19 & 7,1 & 8,3 \\ 21 & 7,2 & 6,9 \\ 23 & 6,9 & 6,3 \\ 26 & 8,4 & 7,6 \\ 34 & 10,1 & 7,1 \\ 42 & 5,8 & 5,0 \\ 54 & 9,3 & 7,5 \\ 56 & 6,4 & 5,7 \\ 74 & 8,5 & 9,4\end{array}$

Опыт проводился в районе (диаметр 150 м) с одинаковыми метеорологическими условиями и одинаковой степенью загрязненности воздуха. Несмотря на это интенсивность коррозии образцов оказалась неодинаковой (наибольшая разница - в два раза), что можно объяснить только разными положениями образцов. Например, образец 42 был прикреплен к западной стенке кирпичного здания, а образец $7-$ к деревянному столбу и направлен на восток. Сравнительно одинаковая степень коррозии была у образцов, установленных в одном направлении на ограде $(19,21$ и 23$)$.

Коррозионные испытания проводились в два периода: первый продолжался 2 месяца (сентябрь и октябрь), второй - около 5 месяцев (с ноября по апрель). Интенсивность коррозии в течение обоих периодов (выражена в миллиграммах за сутки на $1 \partial \mu^{2}$ площади образца) оказалась почти одинаковой, однако несколько большей в первый.

В первый период эксперимента было использовано 77 , во второй 40 образцов. Анализ результатов показал, что для получения наиболее сравнимых данных для образцов необходимы одинаковые микроклиматические условия. С этой целью их надо закреплять на одинаковой выcore, причем подальше от стен домов и других отражающих площадей, а также выбирать для всех образцов одинаковое направление относительно частей света.

При проведении данных опытов не удалось полностью выполнить эти требования. Однако экспонирование нескольких образцов позволило учесть вышеуказанные побочные влияния.

Определение коррозии образцов. Еще до установки образцы былн очищены от окислов металлической щеткой, промыты спиртом и взвешены. После экспонирования они содержались в течение суток при комнагной температуре, затем были взвешены до іп после удаления ржавчины. По потере веса образцами после снятия ржавчины было установлено теоретическое количество гидрированной окиси железа и соответствующий теоретический рост веса образцов при ржавлении. Действительное повышение веса образцов оказалось ниже теоретического на $7,7--75 \%$ в различных случаях.

На рис. 1 приведены данные о потере ржавчины 31 образцом. На оси абсцисс отложена действительная степень ржавления образца и на оси ординат - количество ржавчины, которое сохранилось на образце до конца опыта. Вычисленная прямая линейной регрессии показывает, что потеря ржавчины образцами от ее общего количества существенно не зависит.

По полученным данным можно сделать вывод, что потеря ржавчины, образующейся на образцах в результате действия дождя и ветра, случайна и для определения степени ржавления образцов по повышению их веса не является надежным показателем.

Удаление ржавчины с поверхности образцов производилось механически и с помощью двух химических методов. В первом случае ржавчину удаляли металлической щеткой и шлифовальной бумагой. При химических методах употребляли концентрированную $\mathrm{HCl}$ с добавлением 


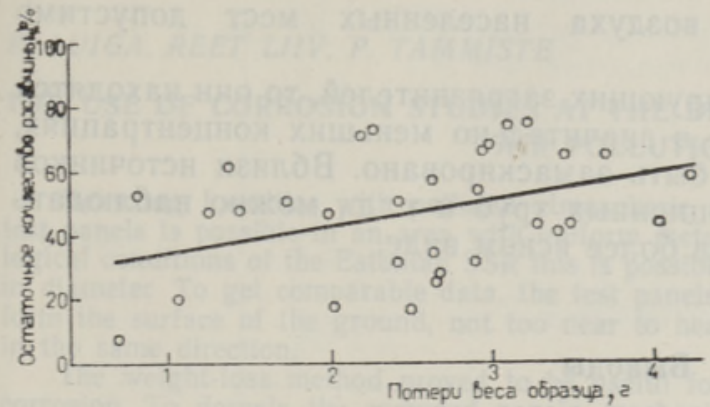

Рис. 1. Потери ржавчины при различной степени коррозии образцов.

$5 \%$-ного родамина В или $10 \%$-ный водный раствор цитрата аммония. Травление производилось при комнатной температуре. При выборе приемлемого метода учитывались потери чистого металла при удалении ржавчины, затрата времени и чистота полученной поверхности образца.

На рис. 2 можно сравнить между собой методы снятия ржавчины с образцов.

Близкне результаты получены при удалении ржавчины механическим способом и травлением $\mathrm{HCl}$ с родамином В. При механической очистке трудно учесть потери чистого металла, однако они относительно небольшие. Более чистая поверхность образцов была также получена с помощью упомянутых двух способов. Время травления образцов $\mathrm{HCl}$ с рода. мином В было 6-12 мин, а цитратом аммония - 24 ч. При травлении раствором цитрата аммония поверхность образцов даже после суточного травления не была чистой, а потери чистого металла были значительными. Хотя $\mathrm{HCl}$ с ингибитором растворял чистый металл, как и раствор цитрата аммония, потери чистого металла благодаря кратковременности травления оказались значительно меньшими.

\section{Обсуждение результатов}

Опыты проводились на небольшой территории, где интенсивность коррозии отдельных образцов зависела от положения их и от наличия местных источников загрязнения.

Разницу в коррозионной интенсивности близкорасположенных, но по-разному установленных образцов можно объяснить ночной тепловой радиацией стен зданий, аккумулированной днем от солнечных лучей. Псэтому температура образов, находившихся близко к зданиям, оказалась выше температуры появления росы, что затормозило коррозию. Подобное явленне наблюдается и при близости образцов к земной поверхности.

Учитывая разницу в установке образцов, получаем зависимость интенсиености коррозии от концентрации корродирующих загрязнителей воздуха - $\mathrm{SO}_{2}, \mathrm{H}_{2} \mathrm{~S}$, паров кислот, галогенидов и др. Наблюдения ряда авторов [j, 7] показывают, что коррозня стали прямолинейно зависит от содержания сернистых соединений в атмосфере, причем это явление наблюдается уже при концентрации $0,03-0,05 \mathrm{Mz} / \mathrm{M}^{3} \mathrm{SO}_{2}$ (санитарными 
нормами для атмосферного воздуха населенных мест допустимо $\left.0,05 \mathrm{me} / \mathrm{M}^{3}\right)$.

Что касается других корродирующих загрязнителей, то они находятся обычно в атмосферном воздухе в значительно меньших концентрациях, чем $\mathrm{SO}_{2}$, и действие их может быть замаскировано. Вблизи источников загрязнения, например вентиляционных труб и т. д., можно наблюдать действие других загрязнителей в более ясном виде.

\section{Выводы}

1. Для получения зависимости интенсивности коррозии от загрязнителей воздуха необходима территория наблюдения с одинаковыми метеорологическими условиями.

2. С целью получения сравнительных данных о загрязненности воздуха образцы надо экспонировать на столбах на одинаковой высоте вдали от зданий и выбирать для всех образцов одинаковую ориентацию относительно частей света.

3. Удобным, быстрым и достаточно точным методом для удаления ржавчины с поверхности образцов является травление концентрированной $\mathrm{HCl}$ с ингибитором.

\section{ЛИТЕ Р А Т У Р А}

1. Т о м а шо в Н. Д., В сб.: Атмосферная коррозия металлов, М., 1951, с. 10.

2. Розен фельд И. Л., Атмосферная коррозия металлов, М., 1960.

3. Бер укшти с Г. К., Че бот а рев Б. В., В сб.: Коррозия и защита металлов, М., 1970 , c. 156.

4. Hudson J. C., Stanners J. F., J. Appl. Chem., 3, 86 (1953).

5. Greenblatt J. H., Pe ar $1 \mathrm{~m}$ an R., Chem. Canada, 14, 21 (1962).

6. U pham J. B., J. Air Poll. Control Assoc., 15, 265 (1965).

7. U ph a m J. B., J. Air Poll. Control Assoc., 17, 398 (1967).

Ннститут кибернетики Академии наук Эстонской ССР
Поступила в редакцию 28/VI 1971

\section{P. LUIGA, REET LIIV, P. TAMMISTE}

\section{KORROSIOONI INTENSIIVSUS KUI ATMOSFÄARIOHU SAASTATUSE HINDAMISE VAHENDEID}

Atmosfääriōhu saastetsentreid on võimalik avastada ja ōhu saastatust hinnata ka selle järgi, kui intensiivselt korrodeeruvad raudplaadid ühtlase ilmastikuga piirkondades. Eesti NSV meteoroloogilistes tingimustes on nii vőimalik saastetsentreid avastada $20-30$-kilomeetrise läbimõõduga aladel. Võrreldavate andmete saamiseks tuleb raudplaadid paigutada maapinnast ühtlasele kõrgusele, eemale soojust kiirgavatest ehitistest ja orienteerida ilmakaarte järgi.

Korrosiooni intensiivsuse määramiseks osutus otstarbekohaseimaks kaalukaomeetod. Rooste eemaldamiseks raudplaatidelt kasutati kas nende mehhaanilist puhastamist või sōövitamist soolhappe vōi ammooniumtsitraadi lahusega. 
P. LUIGA, REET LIIV, P. TAMMISTE

\section{THE USE OF CORROSION STUDIES AT THE DETERMINATION OF ATMOSPHERIC AIR POLLUTION}

Detecting localities with polluted atmospheric air by the corrosion intensity of steel test panels is possible in an area with uniform meteorological factors. Under the meteorological conditions of the Estonian SSR this is possible in areas of about 20 to 30 kilometres in diameter To get comparable data, the test panels have to be fastened at equal heights form the surface of the ground, not too near to heat-radiating buildings, and be oriented in the same direction.

The weight-loss method proved to be useful for determining the amount of metallic corrosion. To descale the corroded panels, mechanical cleaning was used as well as treating the panels with concentrated hydrochloric acid with rodamine inhibitor, or with a solution of ammonium citrate, 